\title{
Key Terrestrial and Space Environment Sources
}

Dale L. Johnson", William W. Vaughan',**

Vaughan WW (D https: / /orcid.org/0000-0003-1982-1506

How to cite

Johnson DL; Vaughan WW (2020) Key Terrestrial And Space Environment Sources. J Aerosp Technol Manag, 12: e0120. https://doi.org/10.5028/jatm.v12.1089

\begin{abstract}
Natural (Terrestrial \& Space) Environment (NE) phenomena play a significant role in the design and flight of aerospace vehicles and in the integrity of the associated aerospace systems and structures. Both the terrestrial environment $[0-90 \mathrm{~km}$ altitude) and the space environment (Earth orbital altitudes) parameters and their engineering application philosophy are given with emphasis on launch vehicle-affected terrestrial environment elements. This paper will describe the key terrestrial and space environment sources: wind; atmospheric; and orbital models used in the design and development of launch/space vehicles.
\end{abstract}

KEYWORDS: Natural Environment, Terrestrial, Space, Design, Launch Vehicles

\section{INTRODUCTION}

This paper no.2 is a continuation of (Johnson/Vaughan JATM 2019) which both present the role of the natural environment used in the design and development of launch vehicles. The space environment impact will be introduced here along with the terrestrial environment interactions.

The design engineering community currently uses six categories of natural terrestrial environment models and databases in Launch Vehicle (LV) design studies. Many of the models and databases used for Saturn/Apollo and early Shuttle designs and operations have been improved or replaced. Table 1 lists the current models and databases recommended for engineering design studies for LVs. Consult the references given here for a complete description of the model or procedure and examples of each.

The databases used to generate these terrestrial environment models usually will not meet the need for specific LV designs, so their outputs must be tailored appropriately as the design process proceeds. Exact, generic natural environment (NE) output examples that correspond to each of the models cannot be presented in this section because the generic mean and sigma values for just one site will not necessarily meet the precise needs of a given vehicle's configuration and mission. Therefore, references are given with the suggestion to tailor the output in consultation with the NE team to meet the exact design risk needs of the proposed LV.

Design engineers must choose, in collaboration with the NE team, the exact engineering application procedures using the natural environmental models or databases to apply in their particular systems. All that can be provided to the design engineers are the models or statistical results derived from the models or from calculations, along with assistance in interpreting and using the NE results derived. However, the above-listed references do give the engineers certain applications and procedures for each of the specific terrestrial models for generic engineering use in vehicle design studies. Johnson (2008), Smith and Adelfang (1998), Geissler (1970), Justus et al. (1990), and Adelfang (1999) are very helpful in that. They also contain very specific instructions regarding procedures needed in applying these NE models to engineering vehicle design analyses.

The NE models presented here represent the best fidelity of the real wind and thermodynamic parameters currently available for use in any vehicle design formulation phase. The Earth's Global Reference Atmosphere Model (GRAM) and the Vector Wind Profile (VWP) models provide the real-time variability needed to stress all of the vehicle's engineering systems (elements). Other, much simpler

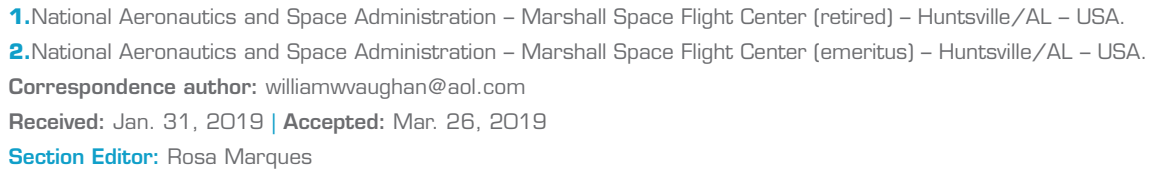


Table 1. Categories of natural terrestrial environment models and their sources.

\begin{tabular}{|c|c|c|}
\hline Category & Application & Source \\
\hline $\begin{array}{l}\text { Thermodynamic } \\
\text { atmospheres }\end{array}$ & $\begin{array}{l}\text { Used in design scenarios for aerodynamic pressure and aerodynamic } \\
\text { heating during launch and, most critical, in return from space or in } \\
\text { suborbital missions, or for preliminary flight test series. }\end{array}$ & $\begin{array}{ll}\text { - } & \text { GRAM-07 (Leslie-Justus 2008) } \\
\text { - } & \text { Range Commander's Council (1983) } \\
\text { - } & \text { NASA (1976) } \\
\text { - } & \text { Johnson (2008) }\end{array}$ \\
\hline $\begin{array}{l}\text { Vector wind profile } \\
\text { (VWP) model }\end{array}$ & $\begin{array}{l}\text { Used in design scenario baselines for dispersion of aero- dynamic } \\
\text { loads attributable to wind profile dispersion (the persistence of } \\
\text { winds over time as a function of the wind load calculations on the } \\
\text { vehicle over that same time). Note: The VWP replaces preliminary } \\
\text { design wind profiles constructed from selected percentiles of } \\
\text { wind speed (scalar wind model) or wind components. It contains } \\
\text { vertical wind shear percentile information. }\end{array}$ & $\begin{array}{l}\text { - } \quad \text { Adelfang et al. (1994) } \\
\text { - } \quad \text { Smith (1976) } \\
\text { - } \text { Adelfang (1999) }\end{array}$ \\
\hline Synthetic wind profiles & Used in preliminary design. & - Johnson (2008) \\
\hline Discrete gust models & $\begin{array}{l}\text { Used to establish structural response to wind gusts. } \\
\text { Both are used in the Shuttle program. }\end{array}$ & $\begin{array}{l}\text { Classic } 9 \mathrm{~m} / \mathrm{s}(30 \mathrm{ft} / \mathrm{s}) \text { gust } \\
\text { model (see Fig. 6) } \\
\text { (Johnson 2008; Adelfang and } \\
\text { Smith 1998) } \\
\text { New NASA gust model } \\
\text { (Adelfang and Smith 1998) }\end{array}$ \\
\hline Turbulence models & $\begin{array}{l}\text { Used in developing vehicle structures and systems for G\&C. } \\
\text { Also used with applications to fuel-budgeting studies. }\end{array}$ & $\begin{array}{l}\text { - GRAM-07 } \\
\text { Power spectrum density/ } \\
\text { continuous turbulence models } \\
\text { (Johnson 2008) }\end{array}$ \\
\hline APRA & $\begin{array}{l}\text { Used in mission planning studies to analyze vehicle design, } \\
\text { mission scenario operability for specified weather constraints. }\end{array}$ & - Smith et al. (1982) \\
\hline $\begin{array}{l}\text { Launch site specific } \\
\text { meteorological } \\
\text { databases (for KSC } \\
\text { and other sites, for } \\
\text { prelaunch, launch, and } \\
\text { landing from the surface } \\
\text { to } 27 \mathrm{~km} \text { (15 nmi) }\end{array}$ & $\begin{array}{l}\text { Used as an input to APRA above. Used to construct the VWP } \\
\text { model. Used in design verification analyses } \\
\text { (surface to } 18 \mathrm{~km}(10 \mathrm{nmi}) .\end{array}$ & $\begin{array}{l}\text { Surface weather data }(30+\mathrm{yr}, \\
\text { hourly) } \\
\text { Monthly Rawinsonde wind } \\
\text { profiles (surface to } 27 \mathrm{~km}[15 \\
\text { nmi], } 19 \mathrm{yr} \text { of data, serially } \\
\text { complete, two profiles/day) } \\
\text { Jimsphere detailed wind profiles, } 150 \\
\text { profiles/month for KSC and VAFB }\end{array}$ \\
\hline
\end{tabular}

*GRAM-07 has the 1990 Turbulence Model (Justus et al, 1990) within it, and has mainly been applied to reentry, descent, and landing studies. Generally, it is not applied to ascent studies.

models and procedures have been used in the past, including use of a Standard Atmosphere; i.e., US76, for initial thermodynamic parametric inputs, and various synthetic scalar and extreme wind profiles for wind inputs, and they still have application relative to some preliminary design studies. The six recommended models or databases indicated in Table 1 are highly recommended. Some examples that the engineer can follow are presented in the next section.

\section{MODEL EXAMPLES}

This section presents some wind and atmosphere parametric examples pertaining to the reference LV and mission profile for a vehicle to be launched from Kennedy Space Center (KSC) on a $90^{\circ}$ flight azimuth with a maximum dynamic pressure ( $\max -q)$ occurring at $\approx 5 \mathrm{nmi}(\approx 9.3 \mathrm{~km})$ altitude. Please note that all equations in this section are in metric units, because the wind and atmospheric equations were originally developed using metric units, and converting to English units may introduce error. However, the tables, figures, and examples list English units first, in keeping with the book style. Also, these same NE 
results were given to the Space Shuttle program in metric units, and were then simply converted by the Shuttle engineering community for their use. The Shuttle was basically designed using both English and metric sets of units.

\section{Winds Aloft Design Application - Vector Wind Profile [WWP] for Vehicle Ascent (>150m [>492 ft]]}

Examples are given in this section for the monthly VWP model that is suitable for application in preliminary engineering design studies for LVs requiring assessments for vehicle trajectory simulations and aerodynamic load dispersions attributable to monthly wind profile dispersions from zero to $27 \mathrm{~km}(15 \mathrm{nmi})$ altitude.

Vehicle design engineers use the VWP model in LV development to establish their aerodynamic load indicator ( $q \alpha$ and $q \beta$, where $q$ is aerodynamic pressure, $\alpha$ is angle of attack, and $\beta$ is angle of sideslip), dispersions, attributable to wind profile dispersion (Adelfang et al. 1994). Choosing at least two extreme months to represent and encompass the seasonal variation of wind profile dispersions is recommended. However, for the reference vehicle example given here, the KSC extreme wind month of February was selected. They employ these derived VWPs in vehicle rigid-body trajectory simulations for proposed vehicle architectures and in developing vehicle guidance and control systems. For any selected reference altitude, the VWP model constructs 12 vertical, synthetic wind profiles that envelop the wind vector dispersion at that altitude for a selected probability level. The construction process (based on quadravariate, normal statistical probability functions) that produces vectors at all the adjacent altitudes is described in Smith and Adelfang (1998) and Adelfang et al. (1994). Given a wind vector at altitude $H$, the wind vectors at each altitude above or below $H$ are conditional bivariate, normally distributed. The given wind vectors at $H$ are defined at $30^{\circ}$ increments on the 99th percentile monthly wind vector ellipse, relative to the vector of the monthly means at $H$. The conditional wind vectors at all adjacent altitudes that intercept the 99 th percentile conditional wind vector ellipse $180^{\circ}$ from the direction of the given wind vector approximates the largest vertical wind vector shear between $H$ and each selected adjacent altitude.

For a $90^{\circ}$ flight azimuth from KSC during the worst wind month of February, the in-plane (IP) and out-of-plane (OP) wind components of the 12 wind profiles (from zero to $27 \mathrm{~km}$ [15 nmi]) for a reference altitude of $9 \mathrm{~km}(5 \mathrm{nmi})$ are listed in Table 2 and illustrated in Fig. 1 as IP and as OP wind components. These synthetic profiles were constructed for the 99th percentile wind vector dispersion at $9 \mathrm{~km}(5 \mathrm{nmi})$ and from the 99 th percentile conditional probability ellipses at all other adjacent altitudes. A complete analysis (not presented here) would use a total of 336 constructed profiles, when they use all 28 of the available reference altitudes (zero to $27 \mathrm{~km}$ [15 nmi]) for all months from the KSC rawinsonde statistical database.
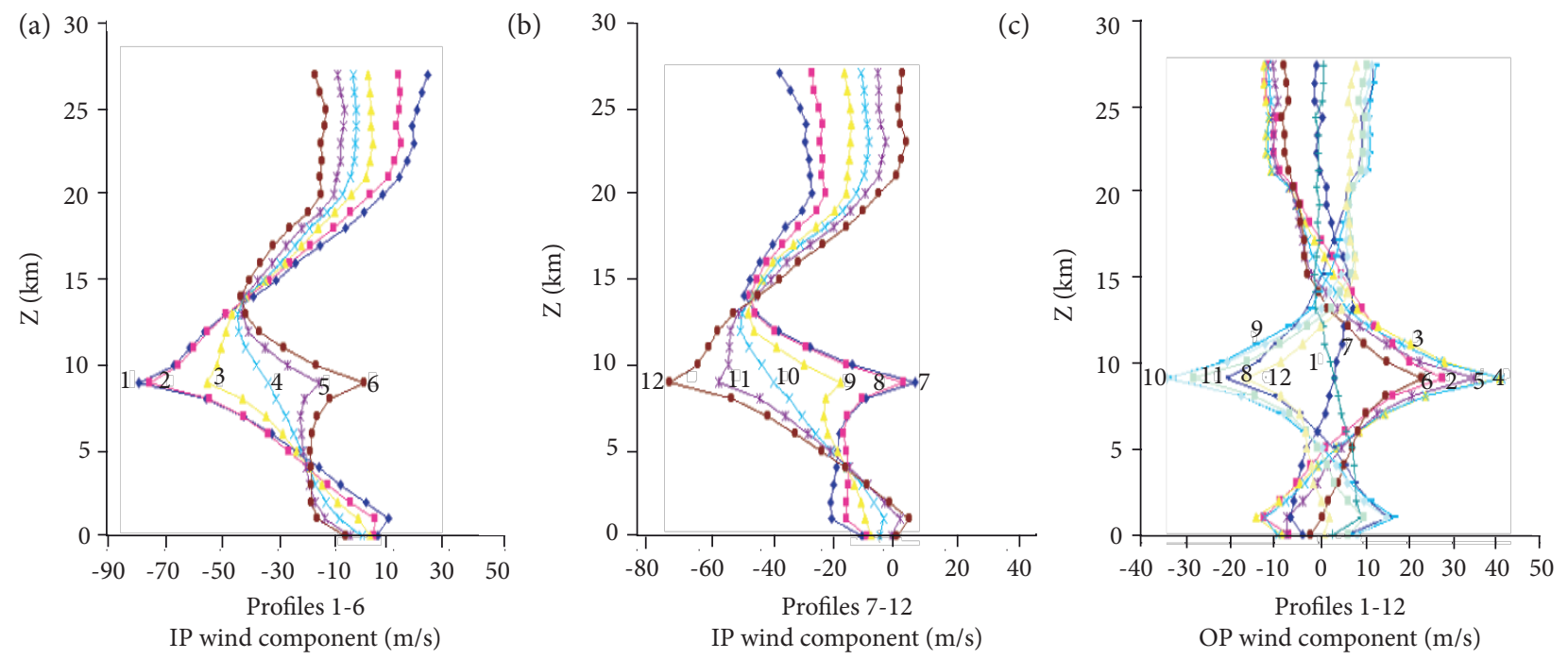

Figure 1. KSC's worst month (February) WWP model design wind component profiles for (a) IP profiles 1-6, (b) IP profiles 7-12, and (c) OP profiles 1-12 (reference height $=9 \mathrm{~km}$ (5 nmi)), IP and OP wind components in $\mathrm{m} / \mathrm{s}$, for flight azimuth $=90^{\circ}$ (graphical presentation of the same information given in Table 2)]. Johnson (2008). 
The engineering team should apply the profiles of the February mean IP and OP wind components while developing the vehicle's ascent guidance, steering commands (VAGSCs) used in the trajectory simulations. A trajectory simulation using this profile of mean wind components then produces the baseline aerodynamic load indicators at each altitude. The aerodynamic load indicators (12 sets) derived from trajectory simulations using the 12 synthetic VWPs for the selected reference altitude of $9 \mathrm{~km}(5 \mathrm{nmi})$ represent the dispersion from the baseline at that altitude. However, as evidenced by the Shuttle and DoD LV operational procedures, the lead indicators can greatly reduce the aerodynamic load indicator dispersion by using a DOL wind profile for the VAGSC. This reduction of aerodynamic loads dispersion attributable to wind profile dispersion has allowed present vehicle programs to achieve enhanced performance and operability objectives.

The VWPs generated with the VWP model contain wavelengths as small as $2 \mathrm{~km}$ (1.1 nmi). It has been demonstrated in two applications - for Space Shuttle and National Launch System - involving VWP model profiles that adding smaller wavelength wind perturbations or gusts to the model profiles has resulted in excessive dispersion (Adelfang et al. 1994; Smith and Austin 1983). Gusts are treated separately in elastic-body dynamic loads analyses.

\section{Procedure}

From Table 2, the VWP model extreme example file contains 25 columns and 28 rows. The first column is the list of altitudes (zero to $27 \mathrm{~km}$ [15 nmi]). Columns 2 through 25 contain IP and OP wind component data in groups of 24 columns of alternating IP and OP wind components for the 12 wind profiles that correspond to the $9 \mathrm{~km}(5 \mathrm{nmi})$ reference altitude. The largest response to wind perturbations is expected to be near the reference altitude because of the large shears generated in that area. They need to implement each of the 12 pairs of the vertical synthetic wind profiles (zero to $27 \mathrm{~km}$ [15 $\mathrm{nmi}$ ) individually within the engineering calculations, to represent extreme wind magnitudes and interlevel wind shear used for design. The VWP program will also allow them to super-impose a gust (see gust paragraph below) at any altitude, with the gust based on the discrete wind gust model having a quasi-square wave shape with amplitude of $9 \mathrm{~m} / \mathrm{s}$ ( $30 \mathrm{ft} / \mathrm{s})$ and a variable gust length from from 60 to 300m (197 to $984 \mathrm{ft}$ ) (Johnson DL, Vaughan WW 2019). The gust is reduced by 0.85 to account for the less-than-perfect correlation between shears and gusts. Above $27 \mathrm{~km}$ ( $15 \mathrm{nmi}$ ) altitude, a scalar shear can be used from NASA/TM-2008-215633 (Johnson 2008), or GRAM may also be run many times in a Monte Carlo mode in determining shears.

\section{Surface Wind Design Application [<150m [<492 ft]]}

Normally, surface winds (or ground winds) are defined as winds that will affect the design of LVs during ground operations or on-pad, and immediately upon launch to $\approx 500 \mathrm{ft}-\approx 150 \mathrm{~m}$ - above the launch site. These surface winds should be considered separately in the design of the LV. Johnson (2008) describes them in more detail.

Design Peak Wind Profile. Vehicle design engineers can use the power law relationship (Eq. 1) to derive a design peak wind profile for any height, $h(33$ to $\approx 500 \mathrm{ft}-10$ to $\approx 150 \mathrm{~m})$, given a known peak wind speed (U18.3) at the reference height of $60 \mathrm{ft}-18.3 \mathrm{~m}$-, and using the windiest exposure period ( $1 \mathrm{~h}$ or 180 days). They are to apply winds from all azimuths (Eq. 1):

$$
U(h)=U_{18.3}(h / 18.3)^{k}
$$

where $k=$ exponent, given by Eq 2:

$$
\left.k=C\left(U_{18.3}\right)^{-3 / 4}\right)
$$

where $U(h)=$ wind speed $(\mathrm{m} / \mathrm{s}) ; U_{18.3}=$ wind speed at $18.3 \mathrm{~m}$ height $(\mathrm{m} / \mathrm{s}) ; h=$ height $(\mathrm{m})$ above natural grade; $k=$ constant, a function of $U_{18.3}$ and surface roughness (unitless); $C=$ surface wind criteria parameter $\left((\mathrm{m} / \mathrm{s})^{3 / 4}\right)$.

The summarized criteria given in Table 3 apply, and values for parameter $C$ should be used as input to Eqs. 1 and 2 in calculating the design peak wind profile for any altitude (surface to $\approx 150 \mathrm{~m}(500 \mathrm{ft})$ ). The given risks and exposure periods are to be used in 
Table 2. KSC worst month (February) VWP model design wind component profiles giving the 12 vector wind model synthetic profiles for each $30^{\circ}$ clock angle plus mean profiles (reference height $=5 \mathrm{~nm}-9 \mathrm{~km}-$, IP and OP wind components $\left(\mathrm{m} / \mathrm{s}\right.$ ), for flight azimuth $=90^{\circ}$ ). After the first column, all units are $\mathrm{m} / \mathrm{s}$

$$
(1 \mathrm{~m} / \mathrm{s}=3.281 \mathrm{ft} / \mathrm{s} ; 1 \mathrm{~km}=0.54 \mathrm{nmi} \text {. }
$$

\begin{tabular}{|c|c|c|c|c|c|c|c|c|c|c|c|c|c|c|c|c|c|c|c|c|c|c|c|c|c|c|}
\hline \multirow{2}{*}{$\begin{array}{l}\text { Alt. } \\
(\mathrm{km})\end{array}$} & \multicolumn{2}{|c|}{$1\left(30^{\circ}\right)$} & \multicolumn{2}{|c|}{$2\left(60^{\circ}\right)$} & \multicolumn{2}{|c|}{$3\left(90^{\circ}\right)$} & \multicolumn{2}{|c|}{$4\left(120^{\circ}\right)$} & \multicolumn{2}{|c|}{$5\left(150^{\circ}\right)$} & \multicolumn{2}{|c|}{$6\left(180^{\circ}\right)$} & \multicolumn{2}{|c|}{7 (210) } & \multicolumn{2}{|c|}{$8\left(240^{\circ}\right]$} & \multicolumn{2}{|c|}{$9\left(270^{\circ}\right)$} & \multicolumn{2}{|c|}{$10\left[300^{\circ}\right]$} & \multicolumn{2}{|c|}{$11\left(330^{\circ}\right)$} & \multicolumn{2}{|c|}{$12\left(360^{\circ}\right)$} & \multicolumn{2}{|c|}{ Mean } \\
\hline & IP & ${ }^{\circ} \mathrm{OP}$ & IP & ${ }^{\circ} \mathrm{OP}$ & IP & ${ }^{\circ} \mathrm{OP}$ & IP & ${ }^{\circ} \mathrm{OP}$ & IP & OP & IP & ${ }^{\circ} \mathrm{OP}$ & IP & ${ }^{\circ} \mathrm{OP}$ & IP & ${ }^{\circ} \mathrm{OP}$ & IP & ${ }^{\circ} \mathrm{OP}$ & IP & ${ }^{\circ} \mathrm{OP}$ & IP & ${ }^{\circ} \mathrm{OP}$ & IP & ${ }^{\circ} \mathrm{OP}$ & IP & OP \\
\hline 0 & 4.5 & -3.6 & 3.0 & -6.6 & 1.6 & -8.2 & -1.2 & -9.0 & -5.1 & -7.0 & -6.8 & -1.8 & -5.9 & 3.2 & -4.3 & 6.2 & -2.9 & 7.8 & -0.1 & 8.6 & 3.8 & 6.6 & 5.5 & 1.4 & -0.65 & -0.21 \\
\hline 1 & 8.2 & -6.2 & 3.3 & -12.2 & -2.5 & -13.8 & -8.8 & -12.0 & -14.2 & -7.0 & -17.0 & 0.8 & -15.6 & 9.5 & -10.7 & 15.4 & -4.9 & 17.1 & 1.4 & 15.3 & 6.8 & 10.2 & 9.6 & 2.4 & -3.70 & 1.62 \\
\hline 2 & 0.4 & -5.5 & -5.1 & -8.6 & -9.6 & -8.8 & -13.8 & -7.3 & -17.5 & -3.6 & -18.9 & 2.3 & -16.1 & 8.5 & -10.7 & 11.6 & -6.21 & 1.8 & -1.9 & 10.3 & 1.7 & 6.6 & 3.1 & 0.7 & -7.88 & 1.48 \\
\hline 3 & -8.5 & -4.7 & -13.2 & -4.8 & -15.2 & -4.1 & -17.5 & -3.1 & -19.5 & -0.1 & -19.1 & 4.5 & -14.9 & 8.1 & -10.2 & 8.2 & -8.2 & 7.4 & -5.9 & 6.5 & -3.9 & 3.5 & -4.3 & -1.1 & -11.70 & 1.68 \\
\hline 4 & -16.3 & -3.7 & -20.1 & -1.7 & -19.7 & -0.2 & -19.8 & 0.1 & -20.7 & 2.1 & -19.1 & 5.8 & -14.1 & 7.9 & -10.3 & 5.9 & -10.7 & 4.4 & -10.6 & 4.1 & -9.8 & 2.1 & -11.3 & -1.6 & -15.21 & 2.11 \\
\hline 5 & -24.2 & -2.6 & -26.9 & 1.6 & -24.2 & 4.1 & -22.4 & 4.0 & -21.8 & 5.2 & -19.2 & 7.6 & -13.8 & 7.6 & -11.0 & 3.3 & -13.7 & 0.9 & -15.5 & 1.0 & -16.1 & -0.2 & -18.7 & -2.6 & -18.97 & 2.49 \\
\hline 6 & -32.8 & -0.2 & -34.1 & 6.1 & -29.1 & 9.1 & -25.1 & 8.7 & -22.5 & 8.7 & -18.6 & 8.8 & -13.1 & 6.2 & -11.8 & -0.1 & -16.8 & -3.2 & -20.8 & -2.8 & -23.4 & -2.7 & -27.3 & -2.9 & -22.95 & 2.98 \\
\hline 7 & -42.6 & 1.6 & -42.7 & 10.7 & -35.0 & 14.9 & -28.0 & 14.4 & -22.6 & 13.0 & -16.8 & 10.7 & -10.6 & 5.0 & -10.5 & -4.1 & -18.2 & -8.3 & -25.2 & -7.8 & -30.5 & -6.4 & -36.3 & -4.1 & -26.58 & 3.31 \\
\hline 8 & -55.9 & 2.4 & -54.8 & 16.7 & -43.1 & 24.0 & -31.3 & 24.0 & -21.5 & 20.9 & -12.4 & 15.1 & -4.5 & 4.4 & -5.7 & -9.9 & -17.4 & -17.2 & -29.2 & -17.2 & -38.9 & -14.1 & -48.1 & -8.3 & -30.24 & 3.40 \\
\hline 9 & -79.8 & 3.5 & -76.0 & 27.6 & -55.6 & 40.5 & -34.3 & 40.9 & -16.2 & 34.8 & -0.3 & 23.1 & 11.3 & 3.5 & 7.5 & -20.6 & -12.9 & -33.5 & -34.3 & -33.9 & -52.3 & -27.8 & -68.3 & -16.1 & -34.26 & 3.50 \\
\hline 10 & -67.4 & 4.1 & -65.7 & 20.4 & -51.9 & 28.2 & -38.2 & 27.1 & -27.3 & 22.5 & -17.4 & 15.2 & -9.0 & 2.7 & -10.7 & -13.6 & -24.4 & -21.4 & -38.2 & -20.3 & -49.1 & -15.8 & -59.0 & -8.4 & -38.18 & 3.39 \\
\hline 11 & -61.8 & 5.3 & -60.5 & 16.6 & -50.6 & 20.5 & -42.0 & 18.6 & -35.3 & 15.2 & -28.7 & 10.3 & -22.5 & 1.4 & -23.8 & -9.9 & -33.6 & -13.9 & -42.3 & -11.9 & -48.9 & -8.6 & -55.6 & -3.6 & -42.13 & 3.32 \\
\hline 12 & -56.7 & 5.7 & -55.5 & 12.4 & -49.0 & 13.4 & -44.4 & 11.3 & -41.0 & 9.3 & -37.1 & 6.6 & -33.0 & 1.2 & -34.2 & -5.5 & -40.7 & -6.5 & -45.3 & -4.3 & -48.6 & -2.3 & -52.6 & 0.4 & -44.84 & 3.49 \\
\hline 13 & -49.2 & 7.7 & -49.1 & 9.7 & -46.8 & 8.6 & -45.0 & 6.3 & -43.6 & 4.2 & -42.0 & 2.1 & -40.3 & -0.6 & -40.5 & -2.7 & -42.7 & -1.6 & -44.5 & 0.7 & -46.0 & $2.8-$ & 47.5 & 5.0 & -44.76 & 3.53 \\
\hline 14 & -39.3 & 7.4 & -41.3 & 7.5 & -42.2 & 6.5 & -42.4 & 4.1 & -42.9 & 1.8 & -43.8 & 0.0 & -44.0 & -0.7 & -42.0 & -0.8 & -41.1 & 0.2 & -41.0 & 2.5 & -40.4 & 4.9 & -39.5 & 6.6 & -41.65 & 3.33 \\
\hline 15 & -31.3 & 6.6 & -33.7 & 5.0 & -35.1 & 3.3 & -36.0 & 0.6 & -38.0 & -1.6 & -40.8 & -2.3 & -42.1 & -0.8 & -39.7 & 0.8 & -38.4 & 2.5 & -37.5 & 5.2 & -35.5 & 7.4 & -32.6 & 8.1 & -36.73 & 2.90 \\
\hline 16 & -24.4 & 5.6 & -26.6 & 3.2 & -28.3 & 1.3 & -30.0 & -1.2 & -32.9 & -3.0 & -36.8 & -3.0 & -38.8 & -0.4 & -36.6 & 2.0 & -34.9 & 3.9 & -33.2 & 6.4 & -30.2 & 8.2 & -26.4 & 8.2 & -31.59 & 2.60 \\
\hline 17 & -16.0 & 3.6 & -19.3 & 0.6 & -22.5 & -0.8 & -24.9 & -2.3 & -28.1 & -3.5 & -32.3 & -3.1 & -34.8 & 0.2 & -31.5 & 3.3 & -28.2 & 4.7 & -25.8 & 6.2 & -22.7 & 7.4 & -18.5 & 7.0 & -25.36 & 1.94 \\
\hline 18 & -6.8 & 3.0 & -11.1 & -1.9 & -16.7 & -3.0 & -19.7 & -3.7 & -22.5 & -4.3 & -26.6 & -4.0 & -30.7 & -0.2 & -26.5 & 4.7 & -20.8 & 5.8 & -17.8 & 6.5 & -15.0 & 7.2 & -11.0 & 6.8 & -18.78 & 1.41 \\
\hline 19 & -0.5 & 1.7 & -5.1 & -3.9 & -10.8 & -4.7 & -13.5 & -4.8 & -16.0 & -5.0 & -20.0 & -4.2 & -25.1 & 0.3 & -20.5 & 5.9 & -14.7 & 6.6 & -12.0 & 6.8 & -9.6 & 6.9 & -5.6 & 6.2 & -12.77 & 0.99 \\
\hline 20 & 6.3 & 1.7 & 1.8 & -5.2 & -4.7 & -6.3 & -7.9 & -6.5 & -10.9 & -6.4 & -15.4 & -5.4 & -22.0 & -0.4 & -17.5 & 6.5 & -11.0 & 7.5 & -7.8 & 7.7 & -4.8 & 7.7 & -0.3 & 6.7 & -7.85 & 0.63 \\
\hline 21 & 12.1 & 0.2 & 8.4 & -8.5 & 0.2 & -10.6 & -5.3 & -10.3 & -10.1 & -9.3 & -16.0 & -6.7 & -22.5 & 0.1 & -18.8 & 8.9 & -10.6 & 11.0 & -5.1 & 10.7 & -0.3 & 9.6 & 5.5 & 7.1 & -5.21 & 0.18 \\
\hline 22 & 14.9 & -0.4 & 10.5 & -9.9 & 1.8 & -11.8 & -3.8 & -11.3 & -8.7 & -10.1 & -15.1 & -7.4 & -23.0 & 0.1 & -18.6 & 9.6 & -9.9 & 11.5 & -4.3 & 11.1 & 0.7 & 9.9 & 7.0 & 7.1 & -4.04 & -0.14 \\
\hline 23 & 17.3 & -0.1 & 12.6 & -10.0 & 2.7 & -11.7 & -3.4 & -11.2 & -8.7 & -10.0 & -15.4 & -7.4 & -24.2 & 0.0 & -19.5 & 9.9 & -9.7 & 11.6 & -3.5 & 11.1 & 1.8 & 10.0 & 8.5 & 7.4 & -3.46 & -0.02 \\
\hline 24 & 16.5 & 0.9 & 11.1 & -9.3 & 2.0 & -11.1 & -3.0 & -11.0 & -7.6 & -10.3 & -14.0 & -8.2 & -23.8 & -0.7 & -18.4 & 9.5 & -9.3 & 11.3 & -4.2 & 11.2 & 0.3 & 10.5 & 6.7 & 8.3 & -3.65 & 0.09 \\
\hline 25 & 18.2 & -0.9 & 12.0 & -11.4 & 1.9 & -11.6 & -3.1 & -10.5 & -7.4 & -9.1 & -13.9 & -6.7 & -25.9 & 0.9 & -19.8 & 11.3 & -9.6 & 11.5 & -4.7 & 10.4 & -0.3 & 9.1 & 6.1 & 6.7 & -3.88 & -0.02 \\
\hline 26 & 19.9 & -0.9 & 12.4 & -11.9 & 1.6 & -12.2 & -3.8 & -11.1 & -8.6 & -9.7 & -15.8 & -7.1 & -28.9 & 1.2 & -21.3 & 12.1 & -10.6 & 12.4 & -5.2 & 11.3 & -0.4 & 9.9 & 6.8 & 7.4 & -4.48 & 0.11 \\
\hline 27 & 22.1 & -0.5 & 11.7 & -11.5 & 1.2 & -12.1 & -4.3 & -11.3 & -9.5 & -10.2 & -17.7 & -7.8 & -32.4 & 1.2 & -22.0 & 12.2 & -11.4 & 12.8 & -6.0 & 12.0 & -0.8 & 10.9 & 7.4 & 8.5 & -5.14 & 0.35 \\
\hline
\end{tabular}


calculating the values of the reference critical design wind speed, and the associated values of $C$ for selected surface-level design applications.

As an example, look at the numbers for tower clearance. If the $5 \%$ risk, critical design peak wind speed value is determined to be $17.7 \mathrm{~m} / \mathrm{s}(58 \mathrm{ft} / \mathrm{s})$ for the windiest 1-h period at $18.3 \mathrm{~m}(60 \mathrm{ft})$, then the peak wind speed value can be calculated at $\approx 150 \mathrm{~m}(500 \mathrm{ft})$ to be $26.2 \mathrm{~m} / \mathrm{s}(86 \mathrm{ft} / \mathrm{s})$.

Table 3. Surface wind criteria to use for certain ground mission phases.

\begin{tabular}{|c|c|c|c|}
\hline Design application & Exposure period & Risk [\%] & $C(\mathrm{~m} / \mathrm{s})^{3 / 4}$ \\
\hline For on-pad exposure (unfueled) & 180 days & 1 & 1.60 \\
\hline For on-pad exposure (fueled) & 1 day & 1 & 1.60 \\
\hline For tower clearance $(0-150 \mathrm{~m}(500 \mathrm{ft}))$ & 1 hour & 5 & 1.60 \\
\hline For ascent loads $(0-150 \mathrm{~m}(500 \mathrm{ft}))$ & 1 hour & 5 & 1.21 \\
\hline
\end{tabular}

Design Steady-State Wind Profile. Equation 3 is used to derive a design steady-state wind $(U(h))$ consistent with the design peak wind profile for on-pad exposures:

$$
\overline{\mathrm{U}}(h)=U(h)\left(1+\left((18.3 / h)\left(0.282-0.435 e_{18.3}^{-(1 / 5) U}\right) /\left(1.98-1.887 e_{18.3}^{-(1 / 5) U}\right)\right)\right)^{-1}
$$

where $U(h)$ is given by Eq. 1 .

This steady-state wind profile shape can then be used in conjunction with spectral and discrete gust models. The particular peak wind profile $U(h)$ to be used in Eq. 3 depends on what the peak wind profile design requirement is; i.e., $U_{18.3}=$ some known inputted wind value.

Peak and Mean Wind Examples. Use of Eqs. 1 through 3 provides them with the peak and steady-state (mean) wind speed profiles. For example, assuming a KSC peak wind of $17.7 \mathrm{~m} / \mathrm{s}(58.1 \mathrm{ft} / \mathrm{s})$ at $18.3 \mathrm{~m}(60 \mathrm{ft})$, Eqs. 1 and 2 result in a peak wind speed of $26.2 \mathrm{~m} / \mathrm{s}(86 \mathrm{ft} / \mathrm{s})$ at about the $150 \mathrm{~m}(500 \mathrm{ft})$ level. This also assumes a $5 \%$ risk for a 1-h exposure (hourly- monthly reference period). To calculate the associated 10-min mean wind speed profile, Eq. 3 results in a mean value of $11.7 \mathrm{~m} / \mathrm{s}(38.4 \mathrm{ft} / \mathrm{s})$ at the $18.3 \mathrm{~m}(60 \mathrm{ft})$ level. These results are also given in Tables 2-2 and 2-6 of Johnson (2008) for these and other heights up to$\approx 150 \mathrm{~m}(\approx 500 \mathrm{ft})$.

On-Pad Gust Environment. The vehicle should be designed to have the elastic body capability of withstanding either the spectral or discrete gust environment from any azimuth. The spectral gust model produces fluctuations from all periods producing significant responses from the LV, while periods of discrete gusts vary over the range of critical periods and the gusts can apply individually.

Spectral Gust. The spectral gust environment at height, $h$, above the natural grade consists of the longitudinal, lateral, and vertical turbulence spectra given by Eq. 4

$$
S(k)=\left[A(h / 18.3)^{a} \times\left(h \bar{U}^{2}{ }_{18.3}\right)\right] /\left[1+B\left((18.3 / h)^{C_{2}} \times k h\right)^{C_{4}}\right]^{b}
$$

where values for the various non-dimensional constants $A, B, a, b, C_{2}$, and $C_{4}$ for KSC, FL, are given in Table 4, and MKS units are understood for all other quantities.

$S(k)$ is a spectral density function at wave number $k$ with units $\mathrm{m}^{2} / \mathrm{s}^{2}(\mathrm{cycle} / \mathrm{m})^{-1}$ and cycles/ $\mathrm{m}$, respectively, and is defined such that integration over the wave number domain zero $\leq k \leq \infty$ yields the variance of the component of turbulence of concern. 
Table 4. Non-dimensional constants for the longitudinal, lateral, and vertical components of turbulence (constant values for the vehicle's on-pad, transportation, and launch-operation phases of the Space Shuttle at KSC, FL, are derived).

\begin{tabular}{|c|c|c|c|c|c|c|c|}
\hline Component & $\boldsymbol{A}$ & $\boldsymbol{B}$ & $\boldsymbol{a}$ & $\boldsymbol{b}$ & $\boldsymbol{C}_{2}$ & $\boldsymbol{C}_{4}$ \\
\hline Longitudinal & 0.807 & 29.035 & -1.63 & 1.972 & 1.000 & 0.845 \\
Lateral and vertical & 0.154 & 9.059 & -0.93 & 2.134 & 0.580 & 0.781 \\
\hline
\end{tabular}

$\overline{\mathrm{U}}_{18.3}$ is the steady-state wind speed, and the steady-state wind profile for this spectral gust model is given by Eq. 3 . The longitudinal component of turbulence is parallel to the steady-state wind vector with the lateral component in the horizontal plane and perpendicular to the longitudinal and vertical components.

Discrete Gust. The discrete gust model consists of longitudinal, lateral, and vertical discrete gusts given by Eq. 5:

$$
V_{i}=\left(A_{i} / 2\right) \times[1-\operatorname{Cos}((2 \pi t) / T)]
$$

where $t=$ time (s); $T=$ gust duration time (s); $A_{i}=$ discrete gust amplitudes $(\mathrm{m} / \mathrm{s}), i=1,2,3$ denote the longitudinal, lateral, and vertical discrete gust amplitudes. $A_{i}$ values are given as functions of the gust duration time, $T$, in Table 5 , but are presented in more engineering detail in Johnson Space Center (1998).

Table 5. Approximate discrete gust amplitudes $[A]$ ) versus gust duration time ( 7 for use in Shuttle on-pad studies. These values are used in Eq. 5 to compute the discrete wind gust speed.

\begin{tabular}{|c|c|c|c|c|c|c|}
\hline \multirow{2}{*}{$\boldsymbol{A} \boldsymbol{i}$ (m/s) } & \multicolumn{9}{|c|}{$\boldsymbol{T}$ (s) } & $\mathbf{1 0}$ & $\mathbf{1 0 0}$ & $\mathbf{1 , 0 0 0}$ \\
\cline { 2 - 8 } & $\mathbf{0 . 0 1}$ & $\mathbf{0 . 1}$ & $\mathbf{1}$ & 10.7 & 10.9 & 10.9 \\
\hline A1 longitudinal & 2.7 & 5.1 & 9.1 & 8.3 & 8.3 & 8.3 \\
\hline A2 lateral & 2.7 & 5.1 & 7.6 & 6.2 & 6.2 & 6.2 \\
\hline A3 vertical & 2.0 & 3.7 & 5.5 & & \\
\hline
\end{tabular}

The engineering team should apply the discrete gusts individually and combine the resulting loads and responses with the loads and responses resulting from the steady-state wind profile with appropriate statistical procedures to determine design loads and responses. A sufficiently wide range of values of $T$ should be selected to encompass the significant periods of the vehicle's response.

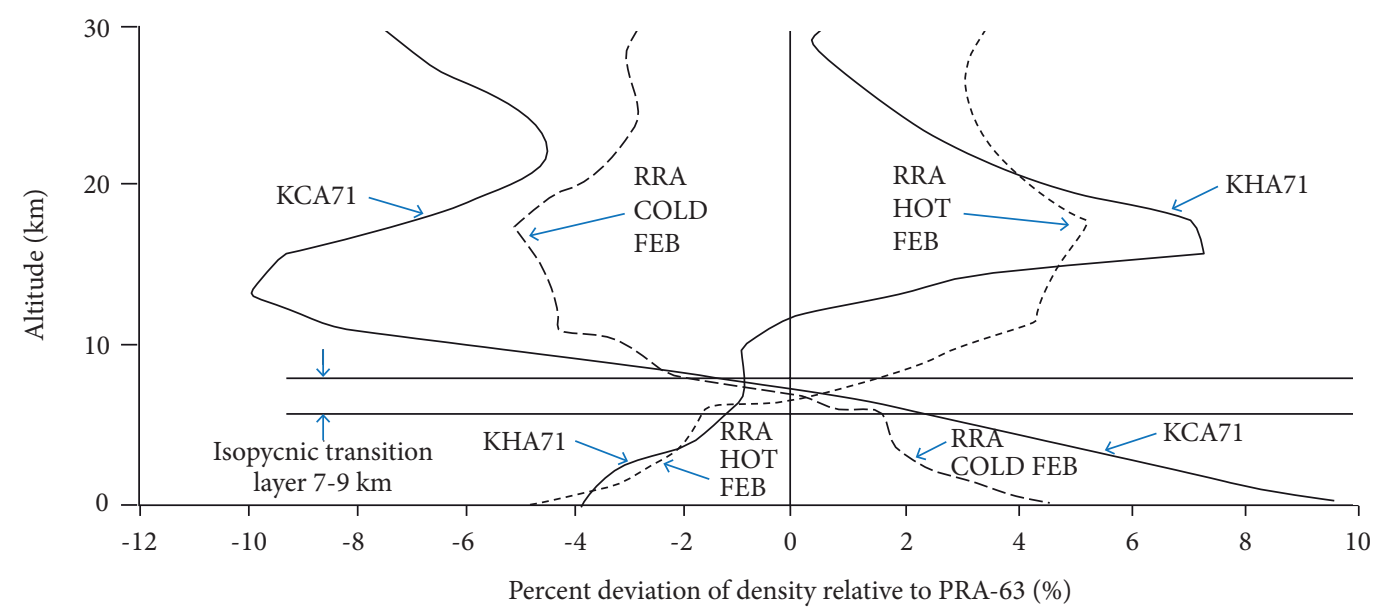

Figure 2. Atmospheric density dispersions of KSC hot (KHA-71) and cold (KCA-71) extreme atmospheres, and RRA dispersion models for February, all relative to the annual Patrick Reference Atmosphere 1963 (PRA-63) (Smith-Weidner 1964). 
Atmospheric Thermodynamic Model Results. Model atmospheres used to design ascent trajectories describe the nominal and extreme variations (with altitude) of atmospheric pressure, temperature, and density. Density is of key importance because of its major influence on aerodynamic heating and dynamic pressure, and hence on trajectory design and structural loads.

Range Reference Atmosphere (RRA) - Kennedy Hot and Cold Atmospheres. For purposes of design, the engineering team should use a nominal, annual KSC RRA (Range Commander's Council 1983), as well as being capable of accommodating a KSC hot and cold extreme density profile, along with their associated pressure and temperature values (Johnson 2008). The monthly KSC RRA can approximate the original KSC hot and cold density profiles from the surface to $70 \mathrm{~km}(38 \mathrm{nmi})$ altitude by using a constructed cold and hot February KSC RRA. They then can derive an engineering model based on the RRA's $2 \sigma$ dispersions that provides an approximate $95 \%$ probability of not exceeding the values at all critical Mach numbers. Figure 2 illustrates these two sets of extreme density profiles. These plots present typical, realistic, extreme-type atmospheric density variation profiles versus altitude above and below the isopycnic (layer of minimal density variability) level. They represent an extreme hot summer and extreme cold winter day over KSC, FL. They were constructed originally to replace the many hundreds of individual profiles that design engineers would need in most engineering studies via Monte Carlo procedures. They can also use the KSC annual RRA to represent nominal conditions.

GRAM-07 Atmosphere - Ascent to Orbit. After lift-off and ascent, the LV goes beyond the influence or boundaries of the KSC launch area. Using the KSC RRA should then be discontinued and the monthly NASA MSFC GRAM-07 design calculations used (Leslie and Justus 2008).

When the vehicle's trajectory latitude and longitude are within a $0.5^{\circ}$ radius of KSC, the RRA should be applied. When the radius is beyond $2.5^{\circ}$, the GRAM-07 should be applied. Between $0.5^{\circ}$ and $2.5^{\circ}$ radiuses, a weighted average of RRA data and GRAM data should be calculated. GRAM-07 has built within it all the RRAs, including KSC's.

As mentioned earlier, GRAM can represent turbulence and perturbations (wind and density) in the atmosphere by using a Monte Carlo-type simulation technique. Design engineers should run $\approx 1,000$ Monte Carlo simulations of GRAM in the initial design studies to properly model and reflect the approximate variability and gradients of the atmospheric, thermodynamic parameters within the real atmosphere.

Reentry, Descent, and Landing. Design engineers also need to apply wind and thermodynamic models to design studies for the reentry and landing of a vehicle. Whatever terrestrial environment models are used for launch and ascent need to be similarly considered for use in descent and landing engineering design studies at the respective design risk level.

Generally, they apply risk-determined, wind environment design criteria for reentry from deorbit to $27 \mathrm{~km}$ (15 nmi) altitude, using GRAM; from 27 to $1 \mathrm{~km}$ (15 to $0.54 \mathrm{nmi}$ ) using RRA or site- specific, radiosonde-summarized statistical data; and from $1 \mathrm{~km}(0.54 \mathrm{nmi})$ to the surfacee using site tower statistical data. Design wind values need to be considered for turbulence and gust, wind shear, surface cross winds, headwinds, and frequency of headwind reversals for their major roles in wind effects on the landing design of the vehicle.

The GRAM thermodynamic model can be used from deorbit altitudes to the location at which the RRA will take effect. The U.S. Standard Atmosphere (NASA 1976) has also been used for certain reentry calculations, but should be used with due consideration for its lack of representativeness of the reentry atmospheric conditions. Atmospheric density and density perturbations generally play a big role in reentry heating and in fuel-budgeting calculations.

\section{ORBITAL ENVIRONMENTS}

Orbital environment parameters apply to LV concept development in two principal ways: (1) When a vehicle includes an upper stage that must operate in orbit; and (2) when a vehicle has reusable elements (spacecraft) that reach orbital altitude and then return to Earth. An important addition is the case of crewed vehicles, in which, because of their very high reliability requirements, the problems with ionizing radiation (classified here as an orbital environment) should be considered even in the launch phase (first and second stage) for the mission-critical avionics. In addition to the information present here and the references cited, the current space and orbital environment information online at the Space Environment Information System (SPENVIS) <http:// www. spen- vis.oma.be/spenvis/> is recommended. Also, the European Space Agency's European Cooperation for Space Standardization presents a good space environment standard document on their website. 


\section{lonizing Radiation Hazard}

At the concept development stage, it is rarely necessary to select electronic parts, so there is usually no need to consider the specifics of the radiation environment. Rather, selecting and planning for the electronic technology and the associated influences on risk, schedule, and cost projections must be stressed. The technology of electronic parts is a rapidly evolving discipline, driven by commercial industry, but developing radiation-tolerant and hardened parts for LVs, with a much smaller market share, typically lags 3 to 5 years. With the ionizing radiation environment in mind during the planning process, the following questions should be addressed:

- What parts are likely to be available in radiation-tolerant forms?

- What test and procurement strategies should be pursued?

- What levels of redundancy should be required for critical systems?

- What functions should be implemented in hardware, and which in software?

- What other design parts might be affected by the hazard?

The Earth-to-orbit and the low-inclination, Low-Earth-Orbit (LEO) radiation environments are relatively benign, but the reliability of the avionics subject to single-event upsets is still an issue. One upset can ruin a mission. Often the problem is solved by designing a redundant system based on Mil-Standard parts, e.g., that single-event upsets caused a reliability concern for the Shuttle's engine controllers while it was sitting on the pad.

When a system will be exposed to high inclination orbits, or high altitude at low inclination $(>2,000 \mathrm{~km}(>1,080 \mathrm{nmi}))$, it crosses a threshold where the vehicle encounters energetic protons trapped in Earth's magnetic field, and the severity of the ionizing radiation environment increases significantly. High inclination in this sense is $\sim 60^{\circ}$ but vehicles encounter trapped particles briefly at inclinations above $30^{\circ}$ in the region known as the South Atlantic Anomaly. Planning for the use of redundant avionics with radiation-tolerant or radiation-hard parts as a baseline is recommended in the early concept development stages for all subsystems requiring high reliability in this environment. If exposure over a long time (more than 6 months) is anticipated, cumulative radiation dose effects on system reliability and performance can also become an issue requiring attention during the developmental phase.

Design Rules of Thumb. Some radiation environment design rules of thumb include the following:

- The ionizing radiation environment consists of multiple particle types in a variety of energy ranges. Similarly, electronic parts have various response modes-single event, latch-up, and dose-related degradation; thus, the matrix of possible failure modes, environments, and parts is quite complex. A description of a part as 'radiation tolerant' or 'radiation hard' is not a sure guide. Test results must be relied on to improve a vehicle's probability of survival.

- Radiation-tolerant versions of a new electronic technology usually lag 3 years or more behind the commercial nonradiationtolerant versions.

- Developing radiation-tolerant versions of electronics typically costs over $\$ 250 \mathrm{k}$ per component and 3 years' development time. Component testing is also expensive - on the order of $\$ 100 \mathrm{k}$ for test components, boards, and facilities and $4 \mathrm{mo}$. in time.

- Redundant system designs can be very effective in improving systems reliability in low-inclination, low-Earth orbits.

- Evaluation of radiation effects on an avionics box containing 100 electronic parts requires about a 1-man-month effort. Because there will be duplication, a box with 500 parts would only require $\approx 3.5$ man-months.

\section{Meteoroids and Orbital Debris}

Orbital debris and meteoroids are generally considered together because they pose a hypervelocity impact hazard to space vehicles. For reusable vehicles, they become, along with other impact hazards, a very major concern in selecting the Thermal Protection System (TPS) and other external surface structures. Other impact hazards include ice or debris that may be shed by other parts of the LV, atmospheric ice and rain that may be encountered during reentry, and rocks lifted from the runway upon landing. The Shuttle has experienced all of these impact hazards. Because of the high energies involved in hyper- velocity impacts, collisions with even small particles will cause damage to areas much larger than the particles. Exposed to the extreme thermal and aerodynamic stress of reentry, the damaged areas may expand, leading to a greater risk of failures. Figure 3 plots an example of orbital debris flux for the year 2005 at various altitudes. The flux would be somewhat less at lower inclination and greater for 


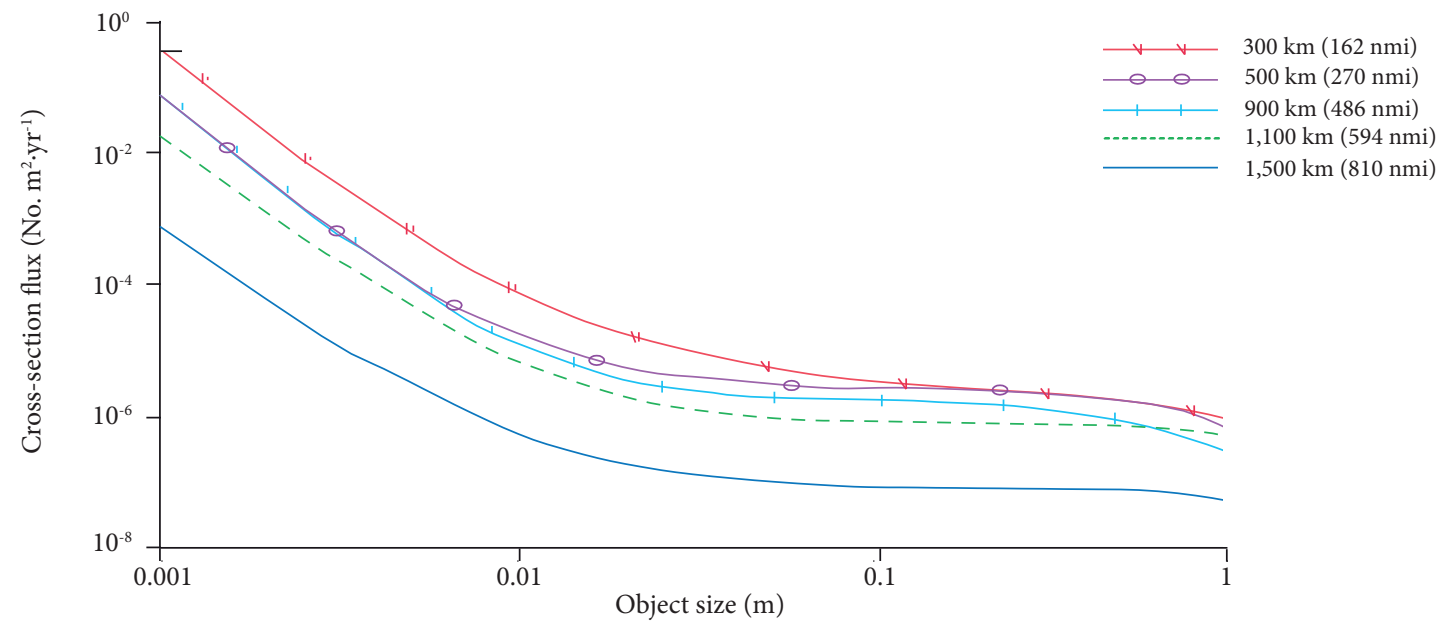

Figure 3. Orbital debris flux in the year 2005 for satellites at various altitudes. Satellite inclination is $70^{\circ}$ ( $1 \mathrm{~m}=3.281 \mathrm{ft}$ ) Liou et al. (2002).

higher inclination satellites. This chart is used to estimate the impact risk to the vehicle, derived from NASA's ORDEM 2000 model (Liou et al. 2002). See the NASA (2019) for additional information.

Window design constitutes another example of an external surface where meteoroid and orbital debris impacts are important. The replacement rate for Shuttle windows is about three windows for every two missions flown. A third example is thermal radiators similar to those on the Shuttle's cargo bay doors. Thin coolant tubing in the radiators is subject to penetration by impact with very small particles, leading to loss of coolant fluid. The risk of this type of failure, which would lead to early mission termination, is typically $1 / 60$ to $1 / 100$ per Shuttle mission, depending on the flight scenario.

Besides designing to limit impact damage, several design requirements imposed on vehicle concepts by the need to limit the future growth of the orbital debris population must be faced. For NASA programs, the requirements are defined by NASA Policy Directive 8710.3a and the companion implementation guide, NASA Safety Standard 1740.14 (NASA 1997a; 1997b). Basically, these documents require the depletion of all onboard stored energy at the end of the mission - venting the remaining propellants; e.g.:

- This procedure helps preclude explosive events that are the primary reason for the ballooning debris population.

- They require flight hardware to not remain in the important LEO and geostationary Earth orbit (GEO) orbital space for more than 25 years beyond the end of the mission. This requirement implies upper stages with perigees above $600 \mathrm{~km}$ (324 nmi) will generally need to retain enough propulsive capability at the end of their mission to deorbit or shift the spacecraft into a safe disposal orbit.

- They limit the number of hardware items - payload shrouds, attachment mechanisms, and any other hazardous parts that may be discarded into space during launch or in orbit.

Design Rules of Thumb. The following meteoroid and orbital debris design rules of thumb apply:

- Craters caused by hypervelocity impact on metals are typically three to five times the diameter of the impacting particle.

- The area damaged by small particle impacts over a 10 -year mission is typically on the order of $1 \%$ of the total, except in brittle or laminated structures where the impact shock or other mechanisms cause the damaged area to grow beyond the impact crater.

- Hypervelocity impact testing can be expected to cost $\$ 3,000$ to $\$ 5,000$ per test, and 10 or more tests may be required to characterize a single structure or material sample. Typical facilities operate at a rate of about one test per day.

- Estimating the future orbital-debris environment is highly uncertain because it strongly depends on the satellite breakup rate and, at low altitudes, solar activity. Damage estimates also contain large uncertainties due to the limited velocity range of test facilities and poor knowledge of orbital debris material and geometric properties. 


\section{Plasma and Spacecraft Charging}

At orbital altitudes, solar radiation ionizes a small portion of the residual gasses to form an electrically neutral plasma with a thermal energy of a few electron volts. Differences in mobility between positive and negative ions, the photoelectric effect, encounters with higher energy electrons in the auroral belts, and other effects can cause spacecraft charging. Potential differences exceeding 1,000 V are possible between different parts of a spacecraft, or between the spacecraft and the space plasma ground potential. Damage to the spacecraft can occur when these potentials cause material sputtering or arc discharges, which may cause burns, or induced currents in the electronics.

In low-Earth, low-inclination orbits, the ion density of the space plasma is high enough that spacecraft potentials tend to dissipate relatively rapidly when compared to the production mechanisms. Thus, charging is seldom a design issue in these orbits. The exceptions are spacecraft such as the International Space Station that use power systems with high voltage $(>100 \mathrm{~V})$ solar arrays. Given this type of power system and the large mobility difference between negative and positive ions, parts of a spacecraft can inadvertently be maintained sufficiently below the ground potential of space plasma that repetitive arcing and concurrent surface damage will occur. The problem can be alleviated by adding a plasma contactor system, but with additional cost and complexity.

For GEO and high-inclination orbits, spacecraft charging is much more of a concern. In this case, high inclination orbits are orbits that reach the auroral oval, usually found near $65^{\circ}$ north and south latitude, but occasionally reaching much lower latitudes because of geomagnetic storms. Even in these orbits, spacecraft charging can be effectively mitigated with proper attention to electrical bonding (grounding) and surface material selection. For example, recommendation is made to avoid large electrically-isolated conductors and external surfaces of strong dielectrics such as silver-backed Teflon thermal blankets. Spacecraft charging processes are not yet fully understood, but if given proper attention during design, associated problems can be successfully reduced. Charging is seldom a concern during the initial concept development phases. See Frederickson for additional information (Frederickson 1996).

Design Rules of Thumb. Some plasma and spacecraft charging design rules of thumb include the following:

- Anticipate spacecraft charging problems when using power systems with high-voltage solar arrays, even in LowEarth, low-inclination orbits.

- Anticipate spacecraft charging problems in high-inclination and GEOs, especially for spacecraft with large external surfaces of strong dielectric materials.

\section{Thermosphere Density and Solar Activity}

The term thermosphere refers to the region of Earth's atmosphere from $\approx 90$ to $500 \mathrm{~km}(\approx 50$ to $270 \mathrm{nmi})$ altitude. Here, gas temperatures increase with altitude and specie concentrations tend toward stratification based on molecular weight. The dominant gasses are atomic oxygen (especially in the lower altitude ranges), helium, and hydrogen. The primary thermospheric effects on spacecraft are drag and atomic oxygen erosion of external surface materials. Atmospheric drag limits a vehicle's orbital lifetime and produces aerodynamic torque that significantly affects system pointing and control.

Difficulty in estimating thermospheric effects on spacecraft comes from the fact that the density of thermospheric constituents is a very strong function of solar heating and solar activity. Diurnal variations of factors of 3 to 5 are common. Similarly, densities smoothed (averaged) over several months show variations exceeding an order of magnitude between the minimum and maxi- mum of the approximate 11-year solar cycle. Short-period variations driven by solar activity, geomagnetic storms, and similar phenomena are nearly as great and add to the smoothed variations. Because solar activity cannot be predicted with high confidence, orbital lifetimes and aerodynamic torques are difficult to predict except in a statistical sense for vehicles below $600 \mathrm{~km}(324 \mathrm{nmi})$. Table 6 illustrates the range of variations. The uncertainties associated with solar activity and thermospheric density feed back into other environmental factors because they have a modulating influence on orbital debris and ionizing radiation, especially on the trapped proton belts and the plasma density. 
Table 6. Estimates of the range of orbital lifetimes for high and low values of solar activity (assumed constant), illustrating the magnitude and the great variability of orbital lifetimes.

\begin{tabular}{|c|c|c|}
\hline Initial Altitude & Area $/$ mass $=0.24 \mathrm{ft}^{2} / \mathrm{lbm}\left[0.05 \mathrm{~m}^{2} / \mathrm{kg}\right]$ & Area $/$ mass $=0.024 \mathrm{ft}^{2} / \mathrm{lbm}\left[0.005 \mathrm{~m}^{2} / \mathrm{kg}\right]$ \\
\hline 300 km (162 nmi) & $\approx 1$ week & 1 to 3 months \\
\hline $500 \mathrm{~km}(270 \mathrm{nmi})$ & 3 months to 3 years & 3 to 25 years \\
\hline 700 km (380 nmi) & $» 4$ years & $» 35$ years \\
\hline
\end{tabular}

See Anderson and Smith (1994) for a description of commonly available, thermospheric density models and tabular data on the statistics of density variation. The MET and JB2006 models are incorporated within the GRAM; they are used for orbital thermodynamic calculations by using the inputs provided in Johnson and Vaughan (2019).

\section{Near-Earth Thermal}

Determining the operating temperatures for systems in near-Earth space requires a thermal balance analysis using internal heat sources and the various external radiative sources and sinks, namely, direct solar radiation, reflected solar (Earth albedo) radiation, Earth's outgoing long-wave radiation (OLR), and the space sink temperature of $3 \mathrm{~K}$. The environmental parameters for this analysis vary with time of year, solar zenith angle, averaging time along the orbital path, and orbital inclination. The resulting temperature also depends upon the orbital $\beta$ angle (minimum angle between a vector in the orbital plane and the Earth-Sun vector), the shortwave absorptance and long-wave emittance of the system's external surfaces, and the thermal time constant of the system. Thus, compromises must be made to simplify the variations so that a few analysis runs can be used to estimate a system's behavior.

Table 7. Estimated thermal environment extremes for low and medium inclination orbits. Albedo and OLR values are corrected to the 'top of the atmosphere' $30 \mathrm{~km}$ (16.2 nmi) above the surface. The $\beta$ angle is defined as the minimum angle between a spacecraft's position vector in the orbital plane and the Earth-Sun vector.

\begin{tabular}{|c|c|c|c|}
\hline & $\begin{array}{c}\text { Averaging Time - Apply at } \\
\text { Solar Noon }\end{array}$ & $\begin{array}{l}\text { Extreme Albedo - Albedo: } \\
\text { OLR, W/ft }\left[\mathrm{W} / \mathrm{m}^{2}\right]\end{array}$ & $\begin{array}{l}\text { Extreme OLR - Albedo: } \\
\text { OLR, W/ft }\left[\mathrm{W} / \mathrm{m}^{2}\right]\end{array}$ \\
\hline Hot cases & $128 \mathrm{~s}$ & $0.51: 16.7(180)$ & $0.26: 30.7(331)$ \\
\hline$\beta=40^{\circ}$ & $896 \mathrm{~s}$ & $0.40: 17.8(192)$ & $0.26: 27.6(297)$ \\
\hline Solar constant $=131.4 \mathrm{~W} / \mathrm{ft}^{2}$ & $30 \mathrm{~min}$ & $0.39: 19.0(205)$ & $0.26: 26.2(282)$ \\
\hline$\left(1,414 \mathrm{~W} / \mathrm{m}^{2}\right)$ & $90 \mathrm{~min}$ & $0.38: 19.0(204)$ & $0.29: 25.5(274)$ \\
\hline Cold cases & $128 \mathrm{~s}$ & $0.07: 25.4(273)$ & $0.39: 14.4(155)$ \\
\hline$\beta=0^{\circ}$ & $896 \mathrm{~s}$ & $0.10: 24.3(262)$ & $0.36: 15.1(163)$ \\
\hline Solar constant $=122.8 \mathrm{~W} / \mathrm{ft}^{2}$ & $30 \mathrm{~min}$ & $0.15: 22.9(246)$ & $0.30: 16.4(176)$ \\
\hline$\left(1,322 \mathrm{~W} / \mathrm{m}^{2}\right)$ & $90 \mathrm{~min}$ & $0.20: 22.2(239)$ & $0.34: 18.6(200)$ \\
\hline
\end{tabular}

Table 7 provides a good compromise set of thermal environmental parameters for a quick analysis of systems in nonpolar orbits. The variation in solar constant reflects the changes in Earth-Sun distance with the time of year. An average solar zenith angle correction was applied to the albedo values. Either the extreme albedo or extreme OLR case will give extreme system temperatures, depending upon the system's surface absorptance and emittance values. To capture the dependence on thermal time constants of the hardware, the 90-min, orbital average values with added short periods of the more severe values associated with the shorter averaging times were modeled. Also applied were the more severe conditions at solar noon. The cold-case extreme temperature will occur in eclipse. See Anderson et al. (2001) for a complete discussion of these thermal environments.

The thermal environmental parameters in polar orbits are more extreme than indicated by Table 7 in two ways: 
1. Mainly because of the increased solar zenith angle characteristics of these orbits, the albedo values are greater. For example, if the $\beta$ angle were $80^{\circ}$ instead of $40^{\circ}$ in the hot case, the zenith angle correction would increase the reported values by 0.16 (additive).

2. The other, more severe extreme is the very low OLR values experienced for short durations over the polar regions. The 128 -s average minimum is $10.3 \mathrm{~W} / \mathrm{ft}^{2}\left(111 \mathrm{~W} / \mathrm{m}^{2}\right)$, the 896 -s value is only $13.7 \mathrm{~W} / \mathrm{ft}^{2}\left(148 \mathrm{~W} / \mathrm{m}^{2}\right)$. For averaging times of $30 \mathrm{~min}$ and longer, a satellite must pass over substantial regions of more temperate values, and the OLR extremes approach the more moderate values in this table. Anderson et al. (2001) present values for analysis of all orbital inclinations and $\beta$ angles.

\section{CONCLUSION}

Terrestrial and space environments associated with the design and development of new launch or space vehicles are presented here. This paper also addresses the basis for the NE guidelines presented, the interpretation of the guidelines, and application to the development of launch/space vehicle design requirements. Any new launch vehicle program or project should consider, early in its development stages, the NE guideline applications suggested in this paper. A better understanding and application of the $\mathrm{NE}$ and its effect on launch vehicles will enable engineering and program management to more effectively minimize program risks and costs, optimize design quality, and successfully achieve mission objectives.

This concludes part two of this three-part paper. The concluding paper no. 3 will be entitled: "Wind Environment Interactions Relative to Launch Vehicle Design.”

\section{AUTHOR'S CONTRIBUTION}

Conceptualization, Johnson DL; Methodology, Johnson DL; Investigation, Johnson DL; Writing - Original Draft, Johnson DL; Writing - Review and Editing, Vaughan WW; Resources, Johnson DL and Vaughan WW; Supervision, Johnson DL and Vaughan WW.

\section{ACKNOWLEDGMENTS}

The authors wish to thank Dr. Stanley I Adelfang, and (the late) Orvel E Smith (both of Stanley Associates) for their most valuable technical and historical terrestrial environment contributions and support. Also to Dr. B.J. Anderson and Dr. Robert E. Smith (both NASA retired) for their space environment contributions.

\section{REFERENCES}

Adelfang SI (1999) User's guide for monthly vector wind profile model. (CR-1999-209759). NASA Technical Report.

Adelfang SI, Smith OE (1998) Gust models for launch vehicle ascent. Presented at: 36th AIAA Aerospace Sciences Meeting; Reno, USA. https://doi.org/10.2514/6.1998-747

Adelfang SI, Smith OE, Batts GW (1994) Ascent wind model for launch vehicle design. J Spacecraft and Rockets 31(3):502-508. https://doi.org/10.2514/3.26467

Anderson BJ, Justus G, Batts W (2001) Guidelines for the selection of near Earth thermal environment parameters for spacecraft design. (TM-2001-211221). NASA Technical Report. 
Anderson BJ, Smith RE (1994) Natural orbital environment guidelines for use in aerospace vehicle development (TM-4527). NASA Technical Memorandum.

[ESA/ECSS] European Cooperation for Space Standardization (2008) Space Environment - E-ST-10-04C. ECCS. http://www.ecss.nl Frederickson AR(1996) Upsets related to spacecraftcharging. IEEE Trans Nucl Sci 43(2):426-441. https: / /doi. org/10.1109/23.490891 Geissler ED (1970) Wind effects on launch vehicles. Slough: Technivision Services.

Johnson DL; Vaughan WW (2019) The Role of Terrestrial and Space Environments in Launch Vehicle Development. J Aerosp Technol Manag, 11: e4719. https://doi.org/10.5028/jatm.v11.1088

Johnson DL (2008) Terrestrial environment (climatic) criteria guidelines for use in aerospace vehicle development, 2008 Revision. (TM2008-215633). NASA Technical Memorandum.

Johnson Space Center (1998) Natural environment design requirements (space shuttle). Houston: NASA.

Justus CG, Campbell CW, Doubleday MK, Johnson DL (1990) New atmospheric turbulence model for shuttle applications. (TM-4168). NASA Technical Memorandum.

Leslie FW, Justus CG (2008) The NASA MSFC Earth global reference atmospheric model - 2007 Version. (TM-2008-215581). NASA Technical Memorandum.

Liou J-C, Matney MJ, Anz-Meador PD, Kessler D, Jansen M, Theall JR (2002) The new NASA orbital debris engineering model ORDEM 2000. (TP-2002-210780). NASA Johnson Space Center Technical Report.

[NASA] National Aeronautics and Space Administration (n.d.) Orbital Debris Program Office. NASA. http://www. orbitaldebris.jsc.nasa.gov/

[NASA] National Aeronautics and Space Administration (1997a) Policy directive 8710.3a - NASA policy for limiting orbital debris generation. Washington: Office of Safety and Mission Assurance.

[NASA] National Aeronautics and Space Administration (1997b) Safety standard 1740.14 - Guidelines and assessment procedures for limiting orbital debris. Washington: Office of Safety and Mission Assurance.

[NASA] National Aeronautics and Space Administration (1976) US standard atmosphere, 1976. (TM-X-74335). NASA Technical Report.

Range Commander's Council (1983) Cape Canaveral Florida - range reference atmosphere O to 70-km Altitude. (361-83). RCC Document.

Smith OE (1976) Vector wind and vector wind shear models $O$ to $27 \mathrm{~km}$ altitude for Cape Kennedy, Florida and at Vandenberg AFB, California. (TM-X-73319). NASA Technical Report.

Smith OE, Adelfang SI (1998) A compendium of wind statistics and models for the NASA space shuttle and other aerospace vehicle programs. (CR-1998-208859). NASA Technical Report.

Smith OE, Weidner DK (1964) A Reference Atmosphere for Patrick AFB, Florida, Annual, 1963 Revision., NASA-TM-X-53139, 23 Sept. 1964.

Smith OE, Batts GW, Willett JA (1982) Atmospheric constraint statistics for the space shuttle mission planning. (TP-2069). NASA Technical Paper.

Smith OE, Austin Jr. LD (1983) Space shuttle response to ascent wind profiles. J Guidance, Control and Dynamics 6(5):355-360. https://doi.org/10.2514/3.19842 